\title{
E-goverment a nivel del País
}

Ing. Álvaro Mejia Pesántez

DOCENTE DE LA CARRERA DE

INGENIERIA DE SISTEMAS




E-goverment o gobierno electrónico, es un concepto que trata sobre el uso de las tecnologías de la información ó TIC'S, el conocimiento y optimización en los procesos internos de gobierno, específicamente del sector público (ministerios, municipalidades, prefecturas, etc.), y en la entrega de los productos y servicios del Estado tanto a los ciudadanos como a la industria, pero siempre buscando una mejora en la eficiencia, eficacia y transparencia.

El Ecuador es un país que pretende alcanzar la modernización de la Administración Pública, utilizando como medio el gobierno electrónico, a través del uso de las TIC'S, pero esto no es suficiente, se necesita de una nueva forma de organización interna, así como una mayor participación de las sociedad.

Esto se conseguirá teniendo en cuenta las siguientes fases de desarrollo y procesos:

$\sum$

- Que sea el Estado quien de una vi sión del modelo de sociedad que estamos construyendo.

- Dar una respuesta más eficaz que la existente a las necesidades y reque rimientos de los ciudadanos.

- Establecer nuevos canales de parti cipación democrática en la toma de decisiones públicas.

- Prestar servicios públicos de una ma nera eficiente y eficaz.

- Ser transparente y controlar el ejercicio del poder público.
- Ser un factor de cohesión social en una nueva sociedad emergente como es la Sociedad del Conocimiento.

- Dar un impulso al desarrollo económico basado en las TIC.

- Que sea el Gobierno el depositario de la garantía de derechos de los ciudadanos en el desarrollo de sus actividades en este nuevo espacio de convivencia que es Internet.

\section{POLÍTICAS A NIVEL DE PAÍS PARA E-GOVERMENT}

El e-goverment no es algo nuevo en nuestro país, es un tema que se ha tratado hace varios años, específicamente se delinearon las primeras iniciativas a nivel de Gobierno en el año 2003 por medio del Consejo Nacional de Telecomunicaciones CONATEL, a través de la Agenda Nacional de Conectividad (ANC), que es una Política de Estado que articula estrategias, programas y proyectos tendientes al desarrollo y difusión de las tecnologías de la información y comunicación (TIC) en áreas como educación, salud, medio ambiente, comercio, industria, turismo, seguridad y gobernabilidad en la sociedad ecuatoriana .

Se han realizado avances en el tema a través de la Corporación Ecuatoriana de Comercio Electrónico CORPECE, que es una asociación empresarial integrada por empresas y profesionales de Internet y Comercio Electrónico, creada con la finalidad

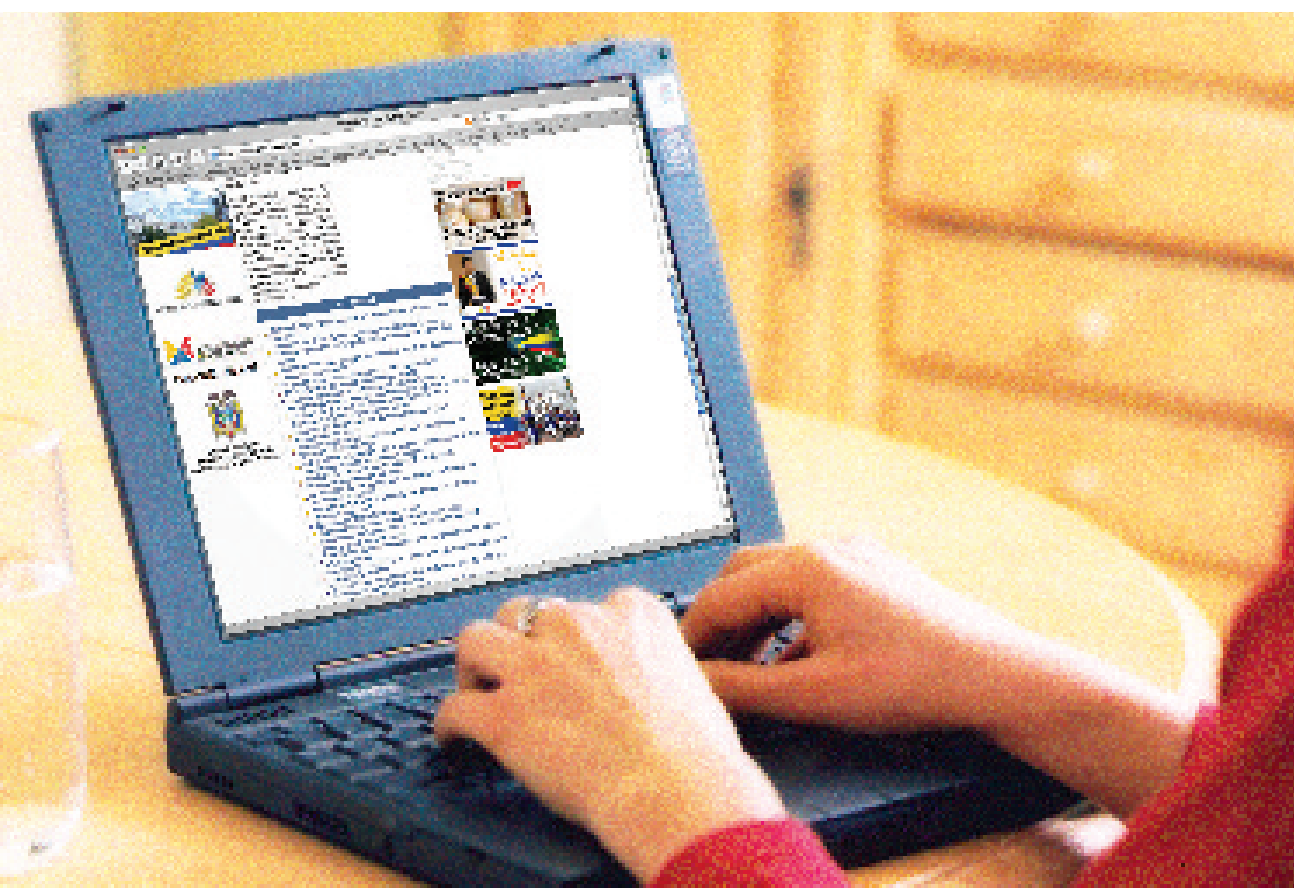


de apoyar el desarrollo de las iniciativas empresariales de Comercio Electrónico e Internet en Ecuador y en la región. Entre los proyectos específicos que han trabajado y están actualmente en marcha son:

- Apoyo en la elaboración y aprobación de la Ley de Comercio Electrónico, Firmas Electrónicas y Mensajes de Datos del Ecuador (Ley No. 67. Registro Oficial Suplemento 557 de 17 de Abril del 2002) y en el Reglamento de Comercio Electrónico, Firmas Electrónicas y Mensajes de Datos del Ecuador (Registro Oficial No. 735 del Martes 31 de Diciembre del 2002).

- Apoyo al Desarrollo del Estándar de la Factura Electrónica en Ecuador

- Coordinación del Country Gateway Ecuador, Portal de Desarrollo del Ecuador.

Así mismo mediante Decreto Ejecutivo $N^{\circ}$ 2471, publicado en el Registro Oficial $N^{\circ} 507$ de 19 de enero del 2005, se expidió el Reglamento General de la Ley Orgánica de Transparencia y Acceso a la Información, cuyo objetivo es garantizar el derecho a solicitar información pública y al libre acceso a fuentes de información.

El 25 de septiembre, se llevó a cabo en Quito, el Encuentro TIC para el DesarroIlo: Gobierno Electrónico y Democracia Digital, evento que se propuso, sensibilizar a líderes comunitarios y autoridades locales sobre las posibilidades que brin- dan las TIC para la gobernabilidad y mostrar experiencias sobre gobierno electrónico y democracia digital en el Ecuador.

Actualmente son varios los asambleístas que están á favor de esta política de Estado, concretamente lo que se pretende alcanzar es una estrategia de desarrollo para establecer una nueva relación Estado y ciudadanía que favorezca la participación, el intercambio de información entre las partes, mejore la calidad y capacidad de respuesta hacia los ciudadanos y se expanda el alcance de los servicios del gobierno a "todos" los sectores, pretendiendo sobre todo controlar la corrupción.

El candidato a asambleísta por el Movimiento Concertación Democrática, Sr. José Pilleggi propuso un "Gobierno electrónico" para "destrabar" y "agilizar" los procesos y trámites públicos. Pilleggi afirmó que el ciudadano ecuatoriano ya no es sólo del país, sino del mundo y que gracias al planteamiento de la creación del "derecho a la tecnología de la información y de la comunicación" de su partido se podrá democratizar los accesos a este servicio.

\section{BENEFICIOS DEL GOBIERNO ELECTRÓNICO}

A continuación se presenta una tabla resumen de las iniciativas y beneficios:

\begin{tabular}{|c|l|l|}
\hline Gobierno electrónico con: & Ejemplos de iniciativas & \multicolumn{1}{|c|}{ Beneficios } \\
\hline ciudadanos & $\begin{array}{l}\text { Acceso a información } \\
\text { Educación Virtual } \\
\text { Trámites en Línea } \\
\text { Consulta y Pago de } \\
\text { Impuestos y Servicios en } \\
\text { Línea }\end{array}$ & $\begin{array}{l}\text { Mayor amplitud de canales, } \\
\text { disminución de costos de } \\
\text { operación, servicios más ági- } \\
\text { les y personalizados, mayor } \\
\text { participación ciudadana }\end{array}$ \\
\hline empresas & $\begin{array}{l}\text { Acceso a información } \\
\text { Obligaciones legales } \\
\text { Pago de impuestos y obliga- } \\
\text { ciones en Línea }\end{array}$ & $\begin{array}{l}\text { Interacciones más rápidas, } \\
\text { disminución de costos de } \\
\text { operación, disminución y/o } \\
\text { eliminación de aspectos nor- } \\
\text { mativos }\end{array}$ \\
\hline instituciones públicas & $\begin{array}{l}\text { Acceso a servicios de infor- } \\
\text { mación entre entes públicos } \\
\text { Provisión de servicios } \\
\text { Centralizados }\end{array}$ & $\begin{array}{l}\text { Mayor rapidez y eficiencia, } \\
\text { disminución de costos de } \\
\text { operación, mejor utilización } \\
\text { de inversiones tecnológicas }\end{array}$ \\
\hline
\end{tabular}




\section{GOBIERNO ELECTRÓNICO DESDE LA ÓPTICA CIUDADANA}

La Internet es una de las herramientas tecnológicas indispensables para la implementación del E-goverment, por medio de esta tecnología se pueden llevar a cabo los procesos y transacciones de una manera mucho más óptima y transparente, con lo que los ciudadanos pueden tener un mayor control sobre la economía del Estado y en especial de la gestión pública, evitando y combatiendo la corrupción, pero no basta tener la conexión y el acceso para que una comunidad o la ciudadanía se integre al nuevo modelo de gestión, es necesario responder las preguntas: por qué se desea tener la conexión, de qué modo se va a utilizar esta tecnología, cómo su apropiación va a convertirse en una herramienta de desarrollo, cómo se capacitará a la gente. Es decir para potencializar el E-goverment en nuestro medio se deben diseñar estrategias de capacitación ciudadana promoviendo la participación de los mismos.

\section{BARRERAS DEL GOBIERNO ELECTRÓNICO}

La participación ciudadana en el gobierno electrónico es una de las principales barreras, puesto que no toda la ciudadanía está en capacidad y posibilidades de acceder al Internet y otras tecnologías relacionadas, debido al nivel de alfabetización, por los recursos económicos y los costos de acceso, el temor al uso de la tecnología, que es un problema generacional.

Otro problema se presenta con las ins tituciones públicas en nuestro país, ya que muy pocas cuentan con tecnología y capacitación respecto a como incorporar E-goverment dentro de su organización, así por ejemplo lo demuestra el organismo Coalición Acceso (Coalición de Organizaciones Sociales por el Acceso a la Información Pública en el Ecuador), que realizó el segundo monitoreo a las páginas Web de doscientas cuarenta y un instituciones públicas que están obligadas a cumplir con lo dispuesto en el artículo 7 de la Ley Orgánica de Transparencia y Acceso a la Información (LOTAIP). Dentro de las conclusiones del informe podemos mencionar:

"De los 219 municipios y 22 consejos provinciales a 137 páginas no se les pudo realizar el monitoreo ya que tenía diferentes problemas: el $92 \%$ no tienen página Web, el $4 \%$ tienen la página en construc ción, el $4 \%$ no tienen la página disponible y el $1 \%$ expiró la página".

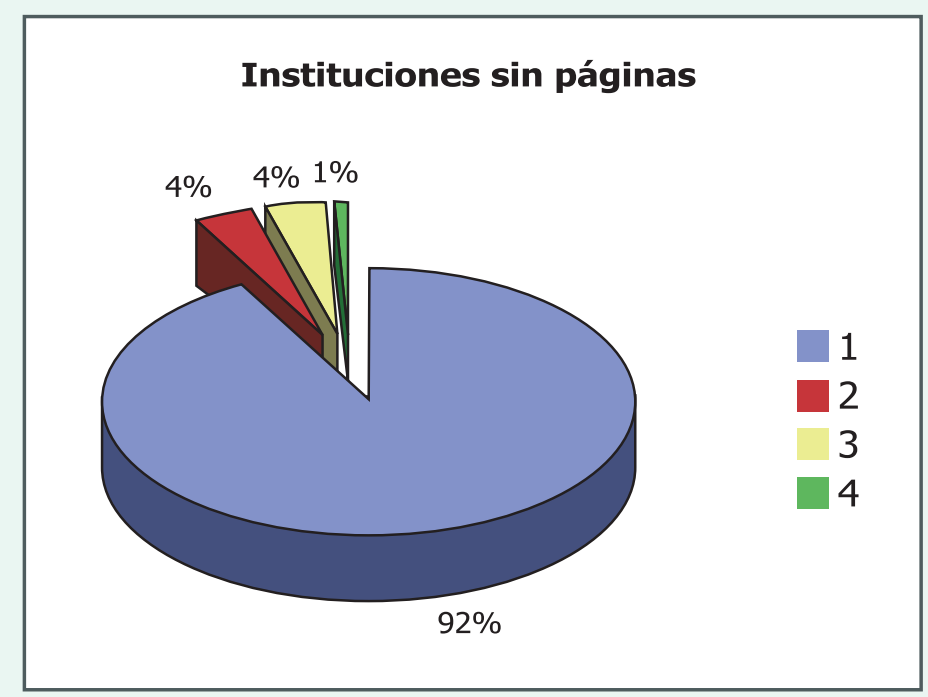

\section{CONCLUSIONES:}

La implementación del Gobierno Electrónico tiene como objetivo primordial lograr un mayor acceso de los ciudadanos a la información y trasparentar los procesos de gestión pública, brindando de esta manera mayores oportunidades para enfrentar un mundo globalizado, en la actual sociedad de la información y el conocimiento.

Para ello se deberán establecer políticas a nivel de país que promuevan la disminución de la brecha o analfabetismo digital, democratizando el acceso a las Tecnologías de la Información y Comunicación para "todos", sin olvidar el hecho de promover una continua capacitación a los ciudadanos para contar con una verdadera herramienta para el desarrollo de nuestro país buscando eliminar la corrupción que tanto daño nos hace. 